\title{
TECHNOLOGY-CONFIDENT TEACHERS ENABLING DEEP E-LEARNING PEDAGOGIES
}

\author{
Roy Rozario \\ Monash University, Australia
}

\begin{abstract}
There are various types of successful teachers in the use of e-learning pedagogies when delivering curriculum in primary school context. That is, novice users, intermediate users and confident/expert users. But little is known about how confident teachers successfully integrate technologies in a dynamic and rapidly changing classroom context to enable quality pedagogies. This study conducted a baseline survey of 42 teachers to select three confident/expert teachers to undergo nine interviews and six classroom observations. An interpretivist and qualitative approach enabled deeper understandings from these teachers, while expansive learning framework facilitated capturing the various interactivities between m-devices, learners, teachers and curriculum content. A case study method using two levels of analysis, thematic and theoretical, helped unfold the key factors that constitute quality e-learning pedagogies. This paper presents two of its five findings, explorative learning and device affordances, that were critical to confident/expert teachers to enable deep learning with technologies using multiple pedagogic strategies.
\end{abstract}

\section{KEYWORDS}

Pedagogy, Classroom E-Learning, Expansive Learning, Interactivity

\section{INTRODUCTION}

E-learning offers a rich potential of deep learning, but the challenge lies with teachers on how they can explore this opportunity to transform their practice (Sharples et al, 2005). According to expansive learning (also called third generation activity theory), classroom learning activities pose the challenge of being unpredictable and uncertain (Engeström, 1987). With e-learning allowing for multiple interactivities between the device and those involved, classrooms have become even more dynamic, thereby posing further complexity in quality pedagogic practice (Wong, 2019).

Many pedagogical concepts/factors in classroom are the cause for learning uncertainties (Gonzalez \& Gómez, 2014; Kumar \& Chand, 2018). For instance, the technologies used, teaching-learning sequence, resources, learning goals, students' difficulties, pedagogy, professional development of the teacher, interactivity of device software and hardware, classroom management and teacher mind-sets, to name a few (Rozario \& Ortlieb, 2015). To illustrate one of these factors, if we took the example of interactivity of the device software, such as an app. They can variously impact the users (teachers, students, teacher-colleagues, etc.) through its affordances on how they interact with the device content through its semiotic features. The ability of the various users to interact with the curriculum content to permit text, audio, video, pictures and spatiality to attain lesson objective can impact on their e-learning (Rozario et al., 2016). This body of knowledge is referred to as Human Computer Interactions (HCI) and allows for understanding e-learning interactions using activity theory (Bakke, 2015). Understanding the processes involved in dynamic e-learning classrooms, especially among technologically-confident teachers, on how they transform surface level teaching-learning practices to enable deep e-learning pedagogies is significant. Few studies focus on how technologically confident teachers can successfully integrate e-learning pedagogies using expansive learning principles.

This study focussed on the device's pedagogical affordances on the users, the context of use and the learning processes involved. Expansive learning provided a sound theoretical framework to capture the various dynamic pedagogical practices involved by technologically-confident teachers as and when they occurred (Mwanza \& Engeström, 2005). Interviews were conducted immediately after classroom 
observations to capture the teaching-learning strategies adopted by teachers to overcome unpredictable and uncertain classroom challenges. The study's results showed five key pedagogical strategies used by technologically-confident teachers to enable deep learning using e-devices. This paper focuses on two strategies of best teacher practice to foster better e-learning pedagogies. Namely, device affordances and explorative learning, that confident teachers use to enable deep learning.

Teachers in this study during classroom sessions regularly used various features of the technologies which impact on their teaching-learning sequences. Because these new features in the technology were never previously been conducted, teachers were often learning on-the-go and skilfully orchestrating the class e-learning activities towards the lesson object. This process is referred to in this paper as explorative learning. This paper pays attention to how teachers orchestrated e-learning using explorative learning skills to successfully attain their end goal. Additionally, this paper also deals with how the affordances of the device impact on pedagogy to facilitate deep learning among students. The interactivity or interface of the device manifests itself through its affordances (Churchill et al., 2014). Therefore, it is no surprise that most definitions, classifications and instructional designs have included the element of device affordances as an integral part of quality pedagogies (Cochrane \& Bateman, 2009). This paper goes beyond the superficial affordances of devices to demonstrate how teachers can orchestrate them into e-learning pedagogies that enable deep learning.

This paper was guided by the research question- What do m-learning device teachers consider as facilitating or inhibiting their pedagogical practices?

\section{METHODOLOGY}

The study used an interpretivists approach because it allowed for many interpretations of reality in primary school context (Ling \& Ling, 2016; Valsiner et al., 2017). It helped collect deep data to inductively answer the research questions asked (Cowling, 2016). Case study as a method also complemented this approach because its methods of data collection, description and explanation, best suited qualitative research (Merriam, 2009). The theoretical lens that the study adopted required to be one that embraced the notion of adaptability and changing context; hence activity theory was most useful (Allen et al, 2011). It was particularly useful because it helped capturing the various interactions (teachers and students) with $\mathrm{m}$-devices (Mwanza-Simwami, 2011).

Case study method allowed the researcher to seek cases that were specific to the need of the study, be present in classroom sessions as an observer, speak to the teachers, collect e-learning artefacts and make field notes relevant to the research questions. The data was collected in two phases. The first phase involved a survey to seek teachers who self-declared that they were confident users of technologies. A pilot-study was implemented to check for robustness of the survey questions after which 42 teachers from three Catholic Primary Schools participated in the survey. Three teacher participants were selected for the second phase of data collection. The second phase involved the researcher observing two classroom sessions per teacher. That is, six observations in total, one initial interview with the three teachers and one post interview after each of the classroom observations, a total of nine interviews.

Ethics clearance was sought at three levels and the Merriam's (2009) ethics checklist served as a guide in this process. The first level involved ethics clearance from the relevant university department, namely, Monash University Human Research Ethics Committee (MUHREC). The second level of ethics clearance was sought from the Catholic Education Offices of the Melbourne and Sale diocese. The third level of ethics clearance was sought from respective participating Catholic Primary Schools. As part of the ethics process the schools were requested to complete Consent and Explanatory forms by the principal, participant teachers, students and parents. During the various data collection stages, the study had no issues with ethics to report. The study addressed the feasibility and trustworthiness by adopting multiple strategies to validate findings, such as, cross case analysis, researcher reflexivity, triangulation and peer review (Merriam, 2009). 


\section{DATA ANALYSIS}

The data-set (teacher interviews, classroom observations, informal interviews, post-classroom observations and e-learning artefacts) was analysed at two levels. The first level involved the 'framework' approach using the Ritchie and Spencer's (2002) model. In this phase the corpus of data was analysed using the five stages of analysis proposed by Ritchie and Spencer (2002). Namely, familiarization, identifying a thematic framework, indexing, charting, mapping and interpretation. The second level involved the theoretical approach using expansive learning theory. This approach allowed for deep analysis of the data-set using tools, such as activity system, activity structure, expansive matrix and expansive cycle, which assisted in analysing, scrutinising and interpreting data.

At the first level of analysis, namely 'framework' approach, the researcher first familiarised himself with the data by immersing into the various audio recordings of teacher interviews, video recordings of the classroom observations, researcher field notes, e-learning artefacts (sample e-activities completed by students), lesson plans and other relevant information provided to the researcher by the teacher. From the corpus of "unstructured and unwieldy" qualitative data, amounting to 80,000 words of interview transcripts, the researcher made notes of recurrent themes, key ideas, indexing, charting, mapping and finding patterns (Bernauer, 2015; Gough \& Scott, 2000; Ritchie \& Spencer, 2002, p.176). Five main themes were finalised. Verbatims and relevant concepts revealed links to overlapping themes that needed further decoding for deep analysis to be done at the theoretical level. Expansive learning concepts like activity structure (operations, actions and activity) and activity system (actors, tools, rules, community, division of labour and object) helped simplify and scrutinise e-learning classroom activities (Engeström; 1987).

\section{FINDINGS}

The study results found five key themes in the data analysis. They are, explorative learning, device affordances and pedagogies, inclusive pedagogies, collaborative and individualised learner centred interactions, and finally challenges as learning opportunity. These concepts emerged as surface level and deep level pedagogic activities. The surface level activities like classroom management, device features and device challenges were no less important, but rather key to enabling deep learning. Teacher participants of this study used surface level activities to convert them into deep level learning using their five pedagogical practices, like a tool-kit of instruments, to orchestrate classes. When these repertoires of pedagogical practices were used, it unintentionally led to quality pedagogies and deep level learning. Only two elements of these findings, that is explorative learning and device affordances, are presented for constraints in word limit and the need to thoroughly understand these concepts. These two themes overlapped during the coding and decoding process and hence are intermingled in their discussion below presented as sub-headings.

\subsection{Explorative Learning}

The study revealed teachers were constantly adapting and changing their classroom practices to accommodate deep learning using a repertoire of best practices they have gained over the years. Teachers only had an imaginary picture of the lesson activity to be conducted and skilfully worked to attain this object. E-learning classroom sessions were quite explorative in nature as many dynamic factors required the teacher to improvise and learn on-the-go making changes to teaching-learning sequences not previously planned. Some dynamic factors, such as, classroom management, cyber safety, device challenges, learner inclusivity, time management, content delivery and deep level learning needs, made teaching-learning complex and unpredictable. The contributing factors to these uncertain e-learning sessions often were consequent to new features of the technologies introduced through their professional learning, unexpected challenges encountered with software and hardware of the device, and e-coaches directly introducing new apps/software or their features.

Many pedagogical strategies were resorted to explore an alternate solution to these challenges. For instance, teachers resorted to their repertoire of skills (five themes of this study's findings) to help explore new ways to deal with these challenges. Participants of this study changed their teaching-learning sequences, included peer-mentorship, inclusive pedagogies, encouraged dialogic interactions, resorted to changed 
classroom management techniques and other practices that emerged as sub-themes. They used their expert knowledge and experience that they had gained over the years as methods/strategies to address new classroom challenges. Additionally, teachers were also mindful, reflective, open-minded, willing to take risks and flexible, even if it meant seeking help from students. They were transparent with their difficulties encountered and openly discussed them with their colleagues and students. They enabled collaborative learning spaces with their colleagues to share their challenges and successes to help same year-level colleagues in their forthcoming lesson activities on the same topic.

Of course, not always the unpredictable nature of e-learning sessions led to challenges but rather successes. Teachers were pleasantly surprised with how smooth and eloquent teaching-learning activities led to unintentional deep learning sessions. Participants in this study anticipated certain difficulties from students on account of device shortage or in trying to conduct a series of complex device interface tasks. However, these tasks were completed very differently as planned but with much ease providing learning results beyond teacher expectations. Kate, one of the teacher participants of this study, reveals her surprise of an unplanned e-learning activity that was not previously introduced-

"I was actually really surprised about how well it worked [use of i-pads]. I didn't expect it [e-learning] to go as smoothly as what it did, because it was really the first time and they did just really pick it up, really quickly".

\subsection{Device Affordances and e-Learning Pedagogies}

The factor of device affordance in enhancing e-learning pedagogies was so significant to this study that it had a spill-over effect to all other findings of this research. In the previous section we understood that teachers often introduced various device affordances during their classroom practice. Data analysis revealed that when these various device affordances were integrated into the curriculum delivery, teachers' pedagogies often enhanced. This was because the devices offered a context relevant, ubiquitous, collaborative, individualised learner-centred and multimodal learning opportunities. Many instances of quality pedagogies occurred during classroom observations. This was done through the ability of the device to deliver the curriculum in multiple ways using both physical and ubiquitous spaces for learners to submit their learning goal using semiotic methods that they were confident and comfortable with. For instance, students who had learning difficulties with writing/typing text used the audio voice recording, drawing, colouring and video features. Additionally, students were able to individually and collaboratively work with technologies to complete tasks. This resulted in a hybrid pedagogical approach that involved inclusive learning, collaborative learning (physical and virtual), user-friendly and individualised learning, new professional learning skills, enhanced interactivity and deep level learning. The benefits were both for students and teachers. As one teacher participant comments,

"...And that's what the great thing about the recording feature is on here, that you do get that [reference to audio recording enabling deep learning]. Whereas if I was to sit down and ask her a question- what do you do at seven O'clock? I probably wouldn't get the same response as when she can just sit there and happily talk to herself and record her message. So, I get a lot more of these videos [using iPads] than at times sitting there and asking them the question".

\section{CONCLUSION}

Classroom teaching-learning are complex activities and many factors accounted for their success (Gonzalez \& Gómez, 2014). Of the many factors, this paper points that successful e-learning classrooms often avail many technological affordances pedagogically. These teachers pedagogically orchestrate teaching-learning sequences using explorative learning to enable deep learning. These pedagogies include one or more of the pedagogies simultaneously occurring. For instance, e-learning pedagogies, such as, individualised learning, collaborative learning, contextual learning and inclusive learning. Expansive learning framework provides a robust approach to unpack these complex classroom activities to understand how we may be able to use these tool-kit of pedagogical practices to enable deep learning (Mwanza-Simwami, 2011). The understanding of this tool-kit of expert/confident teacher pedagogical practices can serve as a guide to bridge the gap between current professional development, teacher standards and the new generational e-learning requirements. 


\section{ACKNOWLEDGEMENT}

I am grateful to my supervisors Assoc. Prof. Joseph Seyram Agbenyega and Dr. Hilary Monk for their ongoing support during my $\mathrm{PhD}$ journey. I also acknowledge the time and commitment provided by research participants to make this project possible. I am thankful to my family for their continued encouragement and finally dedicate this paper to my sister Ruby Rozario who recently passed away.

\section{REFERENCES}

Abiteboul, S. et al, 2000. Data on the Web: From Relations to Semistructured Data and XML. Morgan Kaufmann Publishers, San Francisco, USA.

Allen, D., Karanasios, S. and Slavova, M., 2011. Working with activity theory: Context, technology, and information behavior. Journal of the American Society for Information Science and Technology, 62(4), pp.776-788.

Bodorik P. et al, 1991. Deciding to Correct Distributed Query Processing. In IEEE Transactions on Data and Knowledge Engineering, Vol. 4, No. 3,pp 253-265.

Bernauer, J.A., 2015. Opening the ears that science closed: Transforming qualitative data using oral coding. The Qualitative Report, 20(4), pp.406-415.

Bakke, S., 2015, August. An Activity Theory Approach to Intuitiveness: From Artefact to Process. In International Conference on Human-Computer Interaction (pp. 3-13). Springer, Cham.

Churchill, D., Lu, J. and Chiu, T.K., 2014. Integrating mobile technologies, social media and learning design.

Cochrane, T. and Bateman, R., 2009. Transforming pedagogy using mobile Web 2.0. International Journal of Mobile and Blended Learning (IJMBL), 1(4), pp.56-83.

Cowling, M. A. (2016). Navigating the Path Between Positivism and Interpretivism for the Technology Academic Completing Education Research. In Constructing Methodology for Qualitative Research (pp. 45-58): Springer.

Engeström, Y. (1987). Learning by Expanding: an activity-theoretical approach to developmental research (Helsinki, Orienta-Konsultit).

Gough, S. and Scott, W., 2000. Exploring the purposes of qualitative data coding in educational enquiry: Insights from recent research. Educational Studies, 26(3), pp.339-354.

Gonzalez, M.J. and Gómez, P., 2014. Conceptualizing and describing teachers' learning of pedagogical concepts. Australian Journal of Teacher Education (Online), 39(12), p.13.

Kukulska-Hulme, A., Sharples, M., Milrad, M., Arnedillo-Sánchez, I. and Vavoula, G., 2009. Innovation in mobile learning: A European perspective. International Journal of Mobile and Blended Learning (IJMBL), 1(1), pp.13-35.

Kumar, B.A. and Chand, S.S., 2018. Mobile learning adoption: A systematic review. Education and Information Technologies, 24(1), pp.471-487.

Ling, L. and Ling, P. eds., 2016. Methods and paradigms in education research. IGI Global.

Merriam, S.B., 2009. Qualitative research: A guide to design and implementation (Revised and expanded from qualitative research and case study application in education). Qualitative research science and education. San Francisco: Jossey-Bass

Mwanza, D. and Engeström, Y., 2005. Managing content in E-learning environments. British Journal of Educational Technology, 36(3), pp.453-463.

Mwanza-Simwami, D., 2011. AODM as a framework and model for characterising learner experiences with technology. Journal of e-Learning and Knowledge Society, 7(3), pp.75-85.

Ritchie, J. and Spencer, L., 2002. Qualitative data analysis for applied policy research. The qualitative researcher's companion, 573(2002), pp.305-29.

Rozario, R. and Ortlieb, E., 2015. Using Expansive Learning as a Model for Video Reflection in Teacher Education. In Video Research in Disciplinary Literacies (pp. 287-305). Emerald Group Publishing Limited.

Rozario, R., Ortlieb, E. and Rennie, J., 2016. Interactivity and mobile technologies: An activity theory perspective. In Mobile learning design (pp. 63-82). Springer, Singapore.

Sharples, M., Taylor, J. and Vavoula, G., 2005, October. Towards a theory of mobile learning. In Proceedings of mLearn (Vol. 1, No. 1, pp. 1-9).

Valsiner, J., Chaudhary, N. and Benetka, G., 2017. From methodology to methods in human psychology (p. 115). New York: Springer.

Wong, L.H. and Looi, C.K., 2019. The Conceptual Niche of Seamless Learning: An Invitation to Dialogue. In Seamless Learning (pp. 3-27). Springer, Singapore. 